\title{
Moisture-dependent elastic and strength anisotropy of European beech wood in tension
}

\section{Journal Article}

Author(s):

Ozyhar, Tomasz; Hering, Stefan; Niemz, Peter

Publication date:

2012-08

Permanent link:

https://doi.org/10.3929/ethz-b-000048871

Rights / license:

In Copyright - Non-Commercial Use Permitted

Originally published in:

Journal of Materials Science 47(16), https://doi.org/10.1007/s10853-012-6534-8 


\title{
Moisture-dependent elastic and strength anisotropy of European beech wood in tension
}

\author{
Tomasz Ozyhar $\cdot$ Stefan Hering $\cdot$ Peter Niemz
}

Received: 21 March 2012/Accepted: 24 April 2012/Published online: 8 May 2012

(C) Springer Science+Business Media, LLC 2012

\begin{abstract}
While the general mechanical behaviour of wood is known, its moisture-dependent elastic and strength anisotropy remains little studied. Given the anisotropic and hygroscopic nature of wood, a characterisation of wood mechanical behaviour will require knowledge of its moisture-dependent properties in relation to the three principal axes of anisotropy. The present study examines the influence of the moisture content (MC) on the elastic and strength anisotropy of beech wood (Fagus sylvatica L.). Selected elastic and strength parameters, including the anisotropic Young's moduli, Poisson's ratios, yield and ultimate stress values and the fracture toughness in the TR, $\mathrm{TL}, \mathrm{RT}$ and RL directions, are determined in uniaxial tension and compact tension tests at different moisture conditions. A distinct moisture dependency is shown for the elastic and strength behaviour of beech wood. With the exception of some Poisson's ratios, all investigated elastic and strength parameters are shown to decrease with increasing MC. The two- and three-dimensional representation of the compliance matrix, and the two-dimensional visualisation of a yield surface, provides a valuable overview on the moisture-dependent elastic and strength anisotropy of beech wood.
\end{abstract}

\section{Introduction}

Wood by nature is hygroscopic. As a consequence, its mechanical properties are moisture dependent. Since wood in many applications is exposed to varying climatic

T. Ozyhar $(\bowtie) \cdot$ S. Hering $\cdot$ P. Niemz

Institute for Building Materials (Wood Physics), ETH Zurich, 8093 Zurich, Switzerland

e-mail: ozyhart@ethz.ch conditions, information on its mechanical property and moisture content (MC) relationship is of particular interest. Given the distinctive anisotropy of wood, a complete mechanical characterisation further requires knowledge of the mechanical properties related to the three principal axes of anisotropy (longitudinal L, radial $\mathrm{R}$ and tangential $\mathrm{T}$ ).

The effect of MC on the mechanical properties of wood is an extensively researched topic over the last decades, e.g. [1-5]. A detailed discussion of the literature references covering this field is given in [6]. While selected moisturedependent mechanical properties for numerous wood species have been published in $[1-5,7]$, in general, only few properties were tested for a given property-MC combination in most investigations. Consequently, comprehensive datasets comprising the moisture-dependent anisotropic elastic and strength parameters are missing for most wood species. Elastic and strength parameters based on the threedimensional approach are, however, essential inputparameters required for advanced computational models used in modern civil engineering.

While the influence of MC on the mechanical behaviour of wood in the L direction is relatively well known [6], the behaviour in the perpendicular to the grain directions $(\mathrm{R}$ and $\mathrm{T}$ ), remains scarcely studied. In particular, the moisture-dependent elasticity perpendicular to the grain has been sparsely investigated. So far, only few studies examined the influence of the MC on the elastic properties of wood in the $\mathrm{R}$ and $\mathrm{T}$ directions [2, 3, 5]. In addition, moisture-dependent wood strength, above all the tensile strength in the $\mathrm{R}$ and $\mathrm{T}$ directions, remain widely unknown for most wood species. The available data are limited to a few references [4, 8-10]. Since tensile stress perpendicular to the grain represents the weakest timber point [11-13], its knowledge, especially with regard to the load capacity and failure prediction of wooden structures, is of great 
importance. Further, the ability to withstand failure from fracture when loaded in tension perpendicular to the grain is a crucial topic in wood engineering. Although fracture toughness for wood has been investigated by several authors [14-17], data covering moisture-dependent tensile fracture toughness are limited to a few references [18-22].

The presented study aims to contribute towards a better understanding of the moisture-dependent elastic and strength anisotropy of wood in tension, by providing an extensive set of moisture-dependent mechanical parameters of European beech wood (Fagus sylvatica L.), which can be further used for advanced modelling purposes. While selected moisture-dependent mechanical parameters for European beech wood, have been presented in [5, 23, 24], a comprehensive characterisation of the moisturedependent elastic and strength anisotropy in tension is still lacking.

In the current research, a set of elastic and strength parameters is determined in uniaxial tension and compact tension (CT) tests at different moisture conditions. The parameters evaluated and reported here comprise the anisotropic Young's moduli, Poisson's ratios, tensile yield and ultimate stress values and the critical stress intensity factors in the TR, TL, RT and RL directions.

\section{Materials and methods}

Testing samples

The experimental work performed in this study was carried out on European beech wood (Fagus sylvatica L.) grown in Switzerland near Zurich. The wood used for sample preparation did not contain any growth characteristics such as knots, tension wood or red heartwood.

Three different specimen types, one for the measurement of the tensile properties in the $\mathrm{L}$ direction, a second one for the determination of the tensile properties in the $\mathrm{R}$ and $\mathrm{T}$ directions and a third one for the measurement of the fracture properties in tension, were needed to investigate the mechanical properties examined in this study. A tensile specimen, manufactured according to the DIN 52188 standard [25], was used to measure the tensile properties in the $\mathrm{L}$ direction. Differently, the properties in the $\mathrm{R}$ and $\mathrm{T}$ directions were determined on a "dog-bone" shaped specimen as presented in Fig. 1. Specimens with similar dimensions have already been successfully applied by [26] to determine the tensile Young's moduli and the Poisson's ratios of yew and spruce wood. While a cylindrical shaped specimen is often used to determine the tensile properties of materials, the presented specimen was found to be more appropriate for the measurement of the orthotropic Poisson's ratios. A CT specimen manufactured according to the

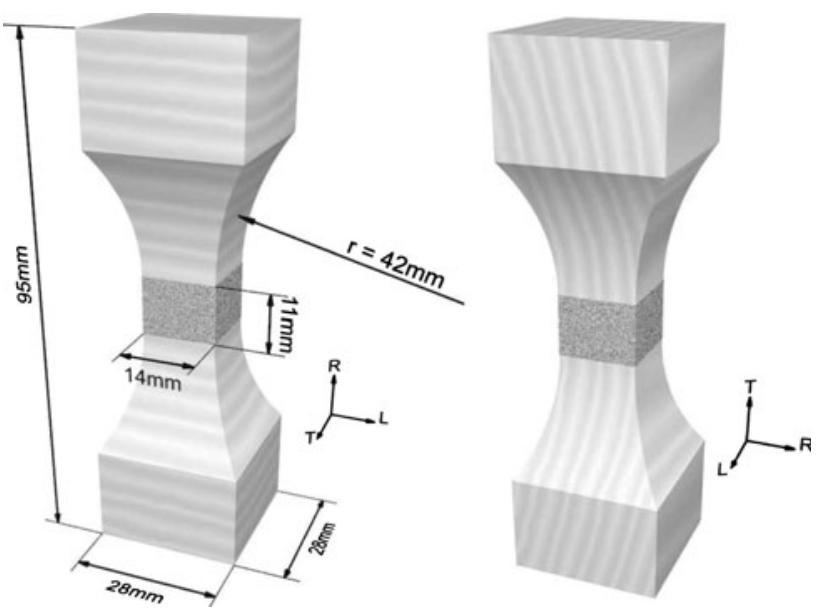

Fig. 1 Profile and dimensions of the tensile specimen used to determine the elastic and strength properties in the $\mathrm{R}$ (left) and $\mathrm{T}$ (right) directions. Figure showing specimen with a high contrast random dot texture in the cross sectional surface area

ASTM E 390-90 standard [27] as shown in Fig. 2a, was used to determine the mode $I$ fracture toughness in tension. Although developed primarily for metal testing, the isotropic solution presented in the standard (see. Eq. 4) proved to be reliable to determine the tensile mode $I$ fracture toughness in the perpendicular to the grain directions [28].

In the present study, four different CT specimen types, with specific orientations to the planes of anisotropy TR, TL, RT and RL were prepared for testing (Fig. 2b).

(a)

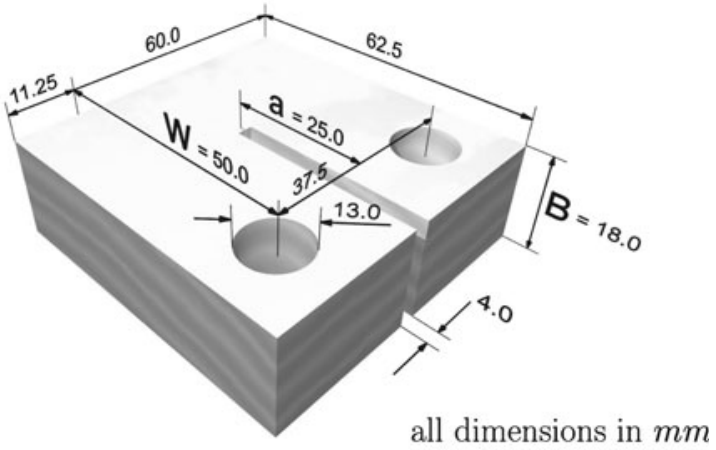

(b)

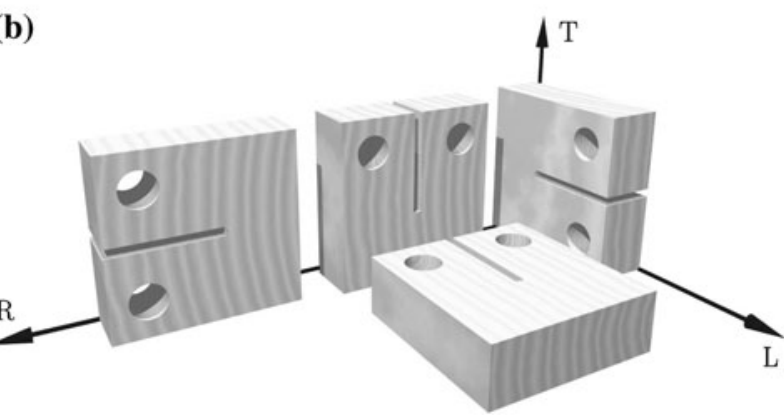

Fig. 2 a Schematic representation of the CT specimen based on the ASTM E 390-90 standard [27]. b CT specimen types used for testing and their orientation to the planes of anisotropy TR, TL, RT, RL 
Experimental methods

\section{Tension test}

Before testing, tensile specimens were randomly divided into four groups and conditioned in climatic chambers at 30 , 65,85 and $95 \%$ relative humidity $(\mathrm{RH})$ at a temperature of $20{ }^{\circ} \mathrm{C}$. After the specimen had reached equilibrium MC, uniaxial tensile tests were carried out using a Zwick Z 100 universal testing machine. All tests were performed at standard climatic conditions $\left(65 \% \mathrm{RH}\right.$ and $\left.20{ }^{\circ} \mathrm{C}\right)$. To minimize the influence of the $\mathrm{MC}$ change, specimens were tested immediately after removal from the climatic chamber. Wood MC was determined by the oven-drying method [7]. A load cell with $100-\mathrm{kN}$ maximum capacity was used for tensile tests performed in the $\mathrm{L}$ direction and a $10-\mathrm{kN}$ load cell for tests in the $\mathrm{R}$ and $\mathrm{T}$ directions. The feed rate was defined in such a way that the failure of the specimen should be reached in $90( \pm 30) \mathrm{s}$. The strains were evaluated using the digital image correlation DIC technique. A highcontrast random dot texture was sprayed on the surface of the specimen to ensure the contrast needed for the evaluation of the displacements. Pictures were taken with a frequency of $2 \mathrm{~Hz}$ of the cross-sectional surface area of the specimen during testing. By means of the mapping software (VIC 2D, Correlated Solution), the surface strains were calculated from the displacements that occurred during deformation. A more detailed description of the strain computation by the DIC technique is given in $[26,29]$.

\section{Calculation of the Young's moduli and the Poisson's ratios}

The Young's moduli $E$ was obtained from the ratio of the stress $\sigma$ to the strain $\varepsilon$ measured in the linear elastic range:

$E_{i}=\frac{\Delta \sigma_{i}}{\Delta \varepsilon_{i}}=\frac{\sigma_{i, 2}-\sigma_{i, 1}}{\varepsilon_{i, 2}-\varepsilon_{i, 1}} \quad i \in R, L, T$

The specific stress-boundaries, $\sigma_{i, 1}$ and $\sigma_{i, 2}$, were set at 10 and $30 \%$ of the expected load at failure, respectively, which was determined in preliminary tests.

The Poisson's ratio $v$, defined as

$v_{i j}=-\frac{\varepsilon_{i}}{\varepsilon_{j}}, \quad i, j \in R, L, T$ and $i \neq j$,

where $\varepsilon_{i}$ represents the active strain component in the load direction and $\varepsilon_{j}$ is the passive (lateral) strain component, which was determined in the linear elastic range from the linear regression of the passive-active strain diagram.

\section{Calculation of the strength parameters}

Two different strength criteria, the ultimate tensile stress $\sigma_{\mathrm{UTS}}$ and the tensile yield stress $\sigma_{\mathrm{Y}}$, were used to characterise the strength behaviour of wood in tension. Using the following relationship,

$\sigma_{\mathrm{UTS}}=\frac{P_{\mathrm{max}}}{A}$,

the $\sigma_{\text {UTS }}$ was calculated from the maximum load $P_{\max }$ at the point of failure and the cross-sectional area $A$ of the specimen. The $\sigma_{\mathrm{Y}}$, defined as the existing stress at the specific yield point, was determined from the measured stress-strain diagram using the "offset yield method" at $0.2 \%$ plastic strain (see Fig. 3a).

\section{Compact tension test}

Before testing, the CT specimens were randomly divided into four groups and conditioned at 50, 65, 85 and $95 \%$ $\mathrm{RH}$ at a temperature of $20^{\circ} \mathrm{C}$. All specimens were loaded until failure with a constant feed rate of $1 \mathrm{~mm} / \mathrm{min}$. In order to initiate the crack, a starter notch was sharpened with a razor blade. A clip on-gauge was used during the test to record the crack mouth opening displacement (CMOD).

Following the ASTM E 390-90 standard [27], the critical stress intensity factor $K_{\text {IC }}$ was calculated using the following equation:
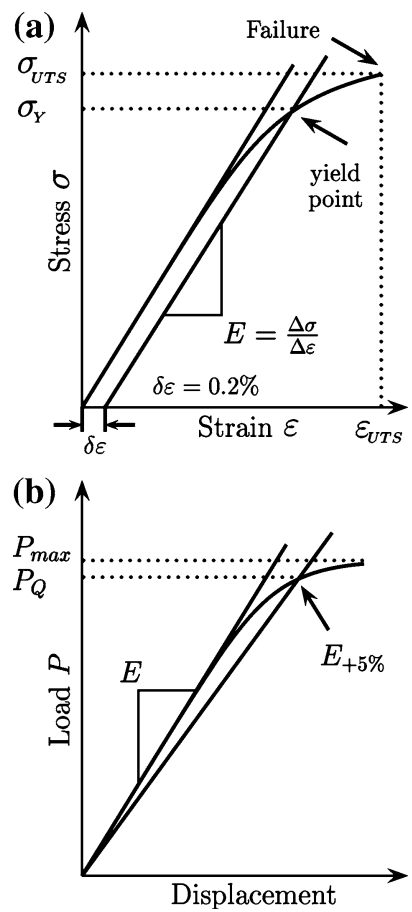

Fig. 3 a Determination of the tensile yield stress (represents the $0.2 \%$ offset yield stress at the specific yield point) from the tensile stress-strain diagram. $\mathbf{b}$ determination of critical force from the load displacement diagram of the CT test 
$K_{\mathrm{IC}}=\frac{P_{\mathrm{Q}}}{B \cdot \sqrt{W}} \cdot f(a / W)$,

where $P_{\mathrm{Q}}$ is the critical force (determined according to Fig. 3b), $B, W$ and $a$ are the dimensions of the CT specimen according to Fig. 2a and $f(a / W)$ is the geometric factor depending on the crack length (for $a / W=0.5$, $a / W=9.66)$

$$
\begin{aligned}
& f(a / W)=(2+a / W) \\
& . \frac{0886+4.64(a / W)-13.32(a / W)^{2}+14.72(a / W)^{3}-5.6(a / W)^{4}}{(1-a / W)^{1.5}}
\end{aligned}
$$

\section{Results and discussion}

Moisture-dependent elastic anisotropy

\section{Young's moduli}

The moisture-dependent Young's moduli for beech wood are presented in Table 1. A decreasing trend with increasing MC is observed for the Young's moduli in all orthotropic directions. The graphical illustration of the measured moduli reveals a nearly linear relationship with the MC (Fig. 4). While the Young's moduli are shown to decrease with increasing $\mathrm{MC}$, the individual moduli $E_{\mathrm{L}}, E_{\mathrm{R}}$ and $E_{\mathrm{T}}$ are affected by the $\mathrm{MC}$ to a different degree. With a decrease of $34 \%$ for $E_{\mathrm{T}}, 31 \%$ for $E_{\mathrm{R}}$ and $23 \%$ for $E_{\mathrm{L}}$ over the measured $\mathrm{MC}$ range, the decline in the $\mathrm{R}$ and $\mathrm{T}$ directions is more pronounced than that in the $\mathrm{L}$ direction. A similar trend, was reported by [6], who summarized literature data for moisture-dependent Young's moduli of several wood species. While the author did not distinguish between the $E_{\mathrm{R}}$ and $E_{\mathrm{T}}$, he showed that, in general, the $E_{\mathrm{L}}$ for wood is less sensitive to MC changes then the moduli in the directions perpendicular to the grain. For Douglas fir, the perpendicular to the grain moduli have been shown to change with MC 8-10 times the rate than for the $E_{\mathrm{L}}$ [3]. While those numbers are clearly higher than the relationship published in this study, the results presented here prove that $E_{\mathrm{R}}$ and $E_{\mathrm{T}}$ are affected by the $\mathrm{MC}$ to a higher degree than the $E_{\mathrm{L}}$.

Only few references cover the anisotropic Young's moduli for European beech wood [24, 30-32]. Even less is known about the moisture dependency of the moduli. The only work known so far to present the moisture-dependent Young's moduli for European beech wood in all orthotropic directions was recently published by [5]. Determined in compression, the Young's moduli MC relationship published by the authors support the relationship obtained for the tensile moduli presented in this study.

According to [12], the elastic anisotropy of hardwoods, expressed by the Young's moduli ratio, is given by

\begin{tabular}{|c|c|c|c|c|c|c|c|c|c|c|c|}
\hline \multirow{2}{*}{$\bar{\omega}(\%)$} & & \multicolumn{3}{|c|}{ Young's moduli (MPa) } & \multicolumn{3}{|c|}{ Anisotropy (MPa) } & \multirow[b]{2}{*}{$\bar{\omega}(\%)$} & \multicolumn{3}{|c|}{ Shear moduli $(\mathrm{MPa})^{\mathrm{a}}$} \\
\hline & & $E_{\mathrm{L}}$ & $E_{\mathrm{R}}$ & $E_{\mathrm{T}}$ & $E_{\mathrm{L}} / E_{\mathrm{T}}$ & $E_{\mathrm{L}} / E_{\mathrm{R}}$ & $E_{\mathrm{L}} / E_{\mathrm{T}}$ & & $G_{\mathrm{LR}}$ & $G_{\mathrm{LT}}$ & $G_{\mathrm{RT}}$ \\
\hline \multirow[t]{4}{*}{5.9} & $\bar{x}$ & 12020 & 1800 & 810 & 14.8 & 6.7 & 2.2 & 9.6 & 1370 & 1010 & 430 \\
\hline & $\operatorname{CoV}(\%)$ & 14.5 & 6.7 & 11.2 & & & & & & & \\
\hline & $n$ & 11 & 10 & 10 & & & & & & & \\
\hline & $\rho\left(\mathrm{kg} / \mathrm{m}^{3}\right)$ & 674 & 683 & 681 & & & & & & & \\
\hline \multirow[t]{4}{*}{11.3} & $\bar{x}$ & 10560 & 1510 & 730 & 14.5 & 7.0 & 2.0 & 12.7 & 1240 & 930 & 380 \\
\hline & $\operatorname{CoV}(\%)$ & 12.5 & 8.1 & 10.3 & & & & & & & \\
\hline & $n$ & 23 & 30 & 32 & & & & & & & \\
\hline & $\rho\left(\mathrm{kg} / \mathrm{m}^{3}\right)$ & 661 & 668 & 654 & & & & & & & \\
\hline \multirow[t]{4}{*}{14.3} & $\bar{x}$ & 9270 & 1340 & 600 & 15.5 & 6.9 & 2.2 & 16.8 & 1110 & 910 & 350 \\
\hline & $\operatorname{CoV}(\%)$ & 12.7 & 10.3 & 9.6 & & & & & & & \\
\hline & $n$ & 10 & 17 & 15 & & & & & & & \\
\hline & $\rho\left(\mathrm{kg} / \mathrm{m}^{3}\right)$ & 659 & 698 & 661 & & & & & & & \\
\hline \multirow[t]{4}{*}{16.3} & $\bar{x}$ & 9200 & 1240 & 530 & 17.5 & 7.4 & 2.4 & 18.7 & 980 & 850 & 330 \\
\hline & $\operatorname{CoV}(\%)$ & 19.7 & 13.1 & 6.7 & & & & & & & \\
\hline & $n$ & 8 & 17 & 16 & & & & & & & \\
\hline & $\rho\left(\mathrm{kg} / \mathrm{m}^{3}\right)$ & 673 & 687 & 658 & & & & & & & \\
\hline
\end{tabular}

Table 1 Moisture-dependent elastic properties for European beech wood

${ }^{a}$ Shear moduli determined by means of ultrasonic waves in a previous study [33]; $\bar{\omega}$, average wood moisture content; $\bar{x}$, mean value; $n$, number of specimens; $\mathrm{CoV}$, coefficient of variation; $\rho$, wood density at $\bar{\omega}=11.3 \%$ 
Fig. 4 Moisture-dependent Young's moduli and Poisson's ratios of European beech in tension
$E_{\mathrm{L}} \rightarrow E_{\mathrm{R}} \rightarrow E_{\mathrm{T}} \approx 20: 1,6: 1$.

The Young's moduli ratios calculated for the specific MC deviate slightly from this relationship (see Table 1). It should be noticed, however, that the relationship presented in [12] represents an average value for several hardwood species. While the results prove the distinctive anisotropy of beech wood, the obtained Young's moduli ratios indicate that the elastic anisotropy remains widely unchanged with MC. This is in accordance with the findings published in [33], where no evidence on the influence of the $\mathrm{MC}$ on the elastic anisotropy for beech wood measured by the ultrasound method could be found.

\section{Poisson's ratios}

The moisture-dependent Poisson's ratios are listed in Table 2. Since the surface area of the TL plane on the tensile specimen in the $\mathrm{L}$ direction was too small for a sufficient strain calculation, the $v_{\mathrm{TL}}$ was not gaugeable. Therefore, the $v_{\mathrm{TL}}$ values were calculated from the relationship between the elastic coefficients given in [12]:

$v_{\mathrm{TL}}=v_{\mathrm{LT}} \cdot E_{\mathrm{L}} \cdot E_{\mathrm{T}}^{-1}$.

With the highest coefficient of variation $\mathrm{CoV}=52 \%$ measured for the $v_{\mathrm{LR}}$, the $\mathrm{CoV}$ values for the Poisson's ratios exceed the values obtained for the Young's moduli.
Similar high $\mathrm{CoV}$ values for tensile Poisson's ratios published by $[26,34]$ point to a natural high variability of the Poisson's ratios. The settlement of the Poisson's ratio values measured at standard climatic conditions with the average values for hardwoods listed in [12], show a reasonable similarity (see Table 2).

Unlike the Young's moduli, the Poisson's ratios do not decrease with MC (Fig. 4). While a slight decreasing tendency is observed for $v_{\mathrm{RL}}$, the $v_{\mathrm{TL}}, v_{\mathrm{TR}}$ and the $v_{\mathrm{RT}}$ are shown to increase with increasing MC. At the same time, no significant influence of MC on the small Poisson's ratios $v_{\mathrm{LR}}$ and $v_{\mathrm{LT}}$ could be experimentally proved.

These results are contrary to the moisture-dependent Poisson's ratios for European beech published by [5], where Poisson's ratios have been shown to decrease slightly with increasing MC. One should note, however, that the Poisson's ratios given in [5] were determined in compression and therefore may not be directly comparable with the tensile Poisson's ratios obtained in this study. Although there is no experimental evidence that tensile and compressive Poisson's ratios can have different values, some presumptions exist suggesting that the elastic behaviour of wood may differ in tension and compression [35]. While no research is known where a direct comparison of the moisture-dependent tensile and compressive Poisson's ratios for wood have been done, one can imagine that a complex cellular material with hierarchical structure 
Table 2 Moisture-dependent Poisson's ratios for European beech wood in tension

\begin{tabular}{|c|c|c|c|c|c|c|c|c|}
\hline & $\bar{\omega}(\%)$ & & $\begin{array}{l}v_{\mathrm{LR}} \\
{[-]}\end{array}$ & $\begin{array}{l}v_{\mathrm{RL}} \\
{[-]}\end{array}$ & $\begin{array}{l}v_{\mathrm{LT}} \\
{[-]}\end{array}$ & $\begin{array}{l}v_{\mathrm{TL}}^{\mathrm{a}} \\
{[-]}\end{array}$ & $\begin{array}{l}v_{\mathrm{RT}} \\
{[-]}\end{array}$ & $\begin{array}{l}v_{\mathrm{TR}} \\
{[-]}\end{array}$ \\
\hline & \multirow[t]{2}{*}{5.9} & $\bar{x}$ & 0.04 & 0.43 & 0.04 & 0.59 & 0.24 & 0.53 \\
\hline & & $\operatorname{CoV}(\%)$ & 38.2 & 19.5 & 47.3 & - & 12.4 & 4.1 \\
\hline & \multirow[t]{2}{*}{11.3} & $\bar{x}$ & 0.04 & 0.43 & 0.04 & 0.58 & 0.31 & 0.61 \\
\hline & & $\operatorname{CoV}(\%)$ & 42.9 & 17.1 & 41.2 & - & 9.8 & 6.7 \\
\hline & \multirow[t]{2}{*}{14.3} & $\bar{x}$ & 0.05 & 0.39 & 0.04 & 0.62 & 0.36 & 0.65 \\
\hline & & $\operatorname{CoV}(\%)$ & 52.4 & 17.3 & 32.3 & - & 8.7 & 7.6 \\
\hline & \multirow[t]{2}{*}{16.3} & $\bar{x}$ & 0.04 & 0.47 & 0.05 & 0.87 & 0.36 & 0.70 \\
\hline & & $\operatorname{CoV}(\%)$ & 19.3 & 21.2 & 40.4 & - & 7.5 & 5.5 \\
\hline \multicolumn{9}{|c|}{ References } \\
\hline [12] & 12.0 & & 0.04 & 0.37 & 0.03 & 0.50 & 0.33 & 0.67 \\
\hline
\end{tabular}

${ }^{a}$ Value calculated from Eq. 7 ; $\bar{\omega}$, average wood moisture content; $\bar{x}$, mean value; $C o V$, coefficient of variation

like wood may exhibit different elastic responses in tension and compression, which could lead to a different Poisson's effect. However, the lack of literature references on moisture-dependent Poisson's ratios inhibits a definitive statement about the observed differences.

\section{Visualisation of the elastic anisotropy}

Twelve independent elastic engineering parameters, namely three Young's moduli $\left(E_{\mathrm{L}}, E_{\mathrm{R}}, E_{\mathrm{T}}\right)$, three shear moduli $\left(G_{\mathrm{LR}}, G_{\mathrm{LT}}, G_{\mathrm{RT}}\right)$ and six Poisson's ratios $\left(v_{\mathrm{LR}}, v_{\mathrm{RL}}\right.$, $\left.v_{\mathrm{RT}}, v_{\mathrm{TR}}, v_{\mathrm{LT}}, v_{\mathrm{TL}}\right)$, are needed to describe the elastic behaviour of wood [12]. Having obtained the Young's moduli as well as the Poisson's ratios, and including the shear moduli determined in a previous study [33], the moisture-dependent elastic anisotropy for beech can be visualised by a two-dimensional representation of the compliance matrix (see Fig. 5a). This can be achieved by converting the engineering parameters into the $6 \times 6$ compliance matrix $\mathbf{S}$ [12].
Displayed by the polar diagrams for the three planes of anisotropy, the load direction-dependent compliance provides a valuable overview of the elastic anisotropy of beech wood. Confirmed by the increasing compliance, the results clearly show that the stiffness of beech continuously decreases with increasing MC. This becomes even clearer when visualised by the so-called deformation bodies displayed in Fig. 5b. Presented earlier by [5, 26, 36], the three-dimensional representation of the compliance matrix is suitable to describe the degree of the material deformation dependent on the load direction.

Moisture-dependent strength anisotropy

\section{Tensile strength}

Table 3 summarises the moisture-dependent strength behaviour of beech wood. Similar to the Young's moduli, the ultimate tensile stress $\sigma_{\text {UTS }}$ values follow a nearly linear relationship with MC (Fig. 6). The results show that, on average, an increase in $\mathrm{MC}$ over the measured $\mathrm{MC}$
Fig. 5 Load-directional dependence of European beech wood compliance in tension at different MC, a via polar diagrams for the principal planes of anisotropy; b by the three-dimensional representation (darker colour indicates lower wood MC). The presented MC levels result from the interpolation of the specific MC for the Young's moduli, Poisson's ratios and shear moduli given in Table 1

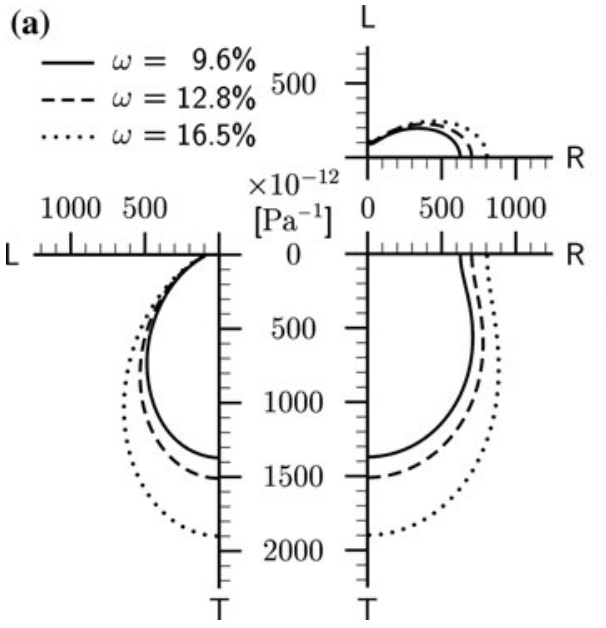

(b)

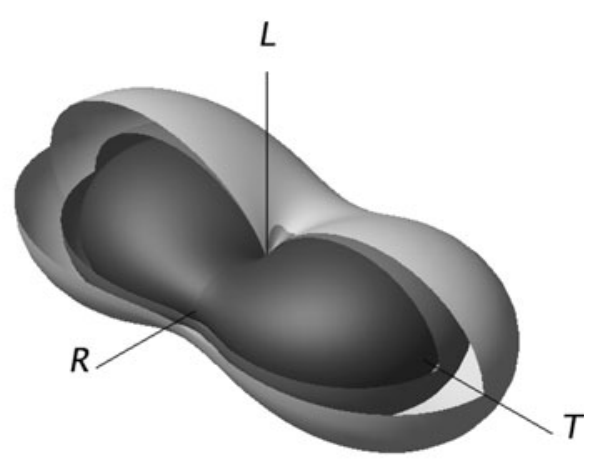


Table 3 Moisture-dependent strength properties for European beech wood in tension

\begin{tabular}{|c|c|c|c|c|c|c|c|c|c|}
\hline \multirow[b]{2}{*}{$\bar{\omega}(\%)$} & & \multicolumn{2}{|l|}{$\mathrm{L}$} & \multicolumn{3}{|l|}{$\mathrm{R}$} & \multicolumn{3}{|l|}{$\mathrm{T}$} \\
\hline & & $\begin{array}{l}\sigma_{\mathrm{UTS}} \\
\left(\mathrm{N} / \mathrm{mm}^{2}\right)\end{array}$ & $\begin{array}{l}\varepsilon_{\text {UTS }} \\
(\%)\end{array}$ & $\begin{array}{l}\sigma_{\mathrm{UTS}} \\
\left(\mathrm{N} / \mathrm{mm}^{2}\right)\end{array}$ & $\begin{array}{l}\sigma_{\mathrm{Y}} \\
\left(\mathrm{N} / \mathrm{mm}^{2}\right)\end{array}$ & $\begin{array}{l}\varepsilon_{\mathrm{UTS}} \\
(\%)\end{array}$ & $\begin{array}{l}\sigma_{\mathrm{UTS}} \\
\left(\mathrm{N} / \mathrm{mm}^{2}\right)\end{array}$ & $\begin{array}{l}\sigma_{\mathrm{Y}} \\
\left(\mathrm{N} / \mathrm{mm}^{2}\right)\end{array}$ & $\begin{array}{l}\varepsilon_{\mathrm{UTS}} \\
(\%)\end{array}$ \\
\hline \multirow[t]{2}{*}{5.9} & $\bar{x}$ & 115.3 & 0.98 & 21.4 & 18.2 & 1.38 & 11.4 & 8.8 & 1.76 \\
\hline & $\operatorname{CoV}(\%)$ & 24.5 & 10.3 & 4.4 & 6.9 & 5.1 & 16.8 & 7.5 & 10.6 \\
\hline \multirow[t]{2}{*}{11.3} & $\bar{x}$ & 96.7 & 1.06 & 19.5 & 14.7 & 1.73 & 8.9 & 7.0 & 1.80 \\
\hline & $\operatorname{CoV}(\%)$ & 28.4 & 19.3 & 9.9 & 15.3 & 12.6 & 18.4 & 6.6 & 27.8 \\
\hline \multirow[t]{2}{*}{14.3} & $\bar{x}$ & 83.6 & 1.13 & 17.1 & 12.5 & 1.99 & 7.8 & 6.1 & 1.89 \\
\hline & $\operatorname{CoV}(\%)$ & 16.9 & 14.2 & 9.5 & 11.5 & 25.4 & 10.3 & 7.7 & 24.6 \\
\hline \multirow[t]{2}{*}{16.3} & $\bar{x}$ & 80.6 & 1.11 & 15.6 & 10.9 & 2.06 & 7.3 & 5.9 & 1.93 \\
\hline & $\operatorname{CoV}(\%)$ & 2.1 & 20.0 & 11.9 & 10.5 & 21.3 & 11.8 & 5.2 & 25.0 \\
\hline
\end{tabular}

$\bar{\omega}$, average wood moisture content; $\bar{x}$, mean value; $\operatorname{CoV}$, coefficient of variation; $\sigma_{\mathrm{UTS}}$, ultimate tensile stress; $\sigma_{\mathrm{Y}}$, tensile yield stress; $\varepsilon_{\mathrm{UTS}}$, ultimate tensile strain (according to Fig. 3a)

range will lead to an $\approx 30 \%$ decrease in strength in all orthotropic directions. The rising ultimate tensile strain $\varepsilon_{\text {UTS }}$ values further exemplify that wood becomes more ductile with increasing MC.

While $\sigma_{\text {UTS }}$, i.e. ultimate stress $\sigma_{\text {US }}$ in tension, is the most common tensile strength criterion used in wood science, it may not always be the most appropriate choice to describe the overall strength behaviour of wood. Since the compression behaviour of wood in the $\mathrm{R}$ and $\mathrm{T}$ directions is characterised by the absence of clear failure and no $\sigma_{\mathrm{US}}$ value exist [12], a direct comparison of the compressive and tensile strength behaviour using the $\sigma_{\mathrm{US}}$ criterion is not

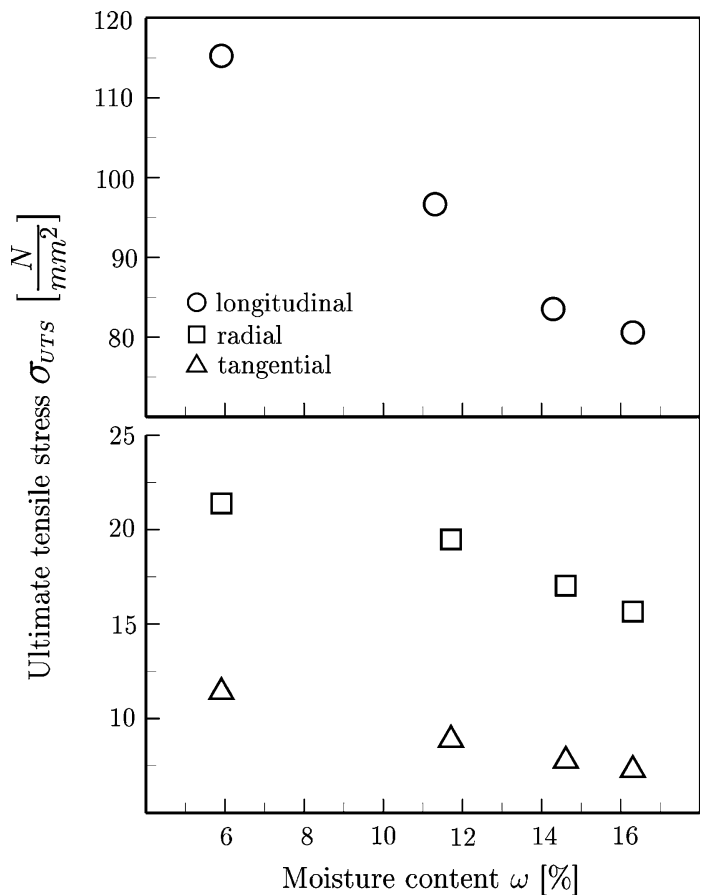

Fig. 6 Moisture-dependent ultimate tensile stress for European beech wood in tension possible. Tensile yield stress $\sigma_{\mathrm{Y}}$, often referred to as the strength in engineering, is therefore introduced to enable a comparison of the tensile and compressive strength behaviour (Table 3). Analogue moisture-dependent yield stress values for European beech wood measured under compression have been recently published by [37].

Applying the yield condition given in [38, 39], the tensile strength behaviour of beech wood can be visualised for all principal planes of anisotropy (Fig. 7). Using the $\sigma_{\mathrm{Y}}$ values presented in Table 3, the yield surface was determined for all measured MC levels. Since the $\sigma_{\mathrm{Y}}$ represents the point where the material begins to plastically deform, the surface provides valuable information about the position of the transition zone between the elastic and plastic region in the stress-strain diagram. In the presented yield surface (see Fig. 7), the stress state displayed below the lines forming the surface represents the elastic and the stress state above the plastic regions of the mechanical behaviour. Calculating the average $\sigma_{Y}$ values for the different MCs, the uniaxial anisotropic tensile strength is described by the ratio

$L \rightarrow R \rightarrow T \approx 13,6: 2: 1$.

\section{Fracture toughness}

While the tensile properties in this study were determined on clear wood specimens, in reality, wood may contain some imperfections which will have an impact on the mechanical performance of the material. Among others, crack in the wood structure is a factor that will considerably affect the strength behaviour of wood. Fracture toughness, defined as the ability of a material containing crack to withstand failure, is therefore one of the fundamental material properties desired in wood engineering.

Similar to the uniaxial strength in tension, the tensile fracture toughness of beech wood declines with increasing MC (Table 4). This is displayed by the stress intensity 
Fig. 7 Moisture-dependent yield surface for European beech wood in tension

Table 4 Moisture-dependent tensile fracture properties for European beech wood a Specimen type according to Fig. 2b (first letter indicates the load direction, second letter gives the direction of crack propagation); $\bar{\omega}$, average wood moisture content; $\bar{x}$, mean value; $n$, number of specimens; $\mathrm{CoV}$, coefficient of variation; $\rho$, wood density at $\bar{\omega}=14.4 \%, P_{\mathrm{Q}}$, critical force (according to Fig. $3 b) ; K_{\mathrm{IC}}$, stress intensity factor (calculated from Eq. 4)

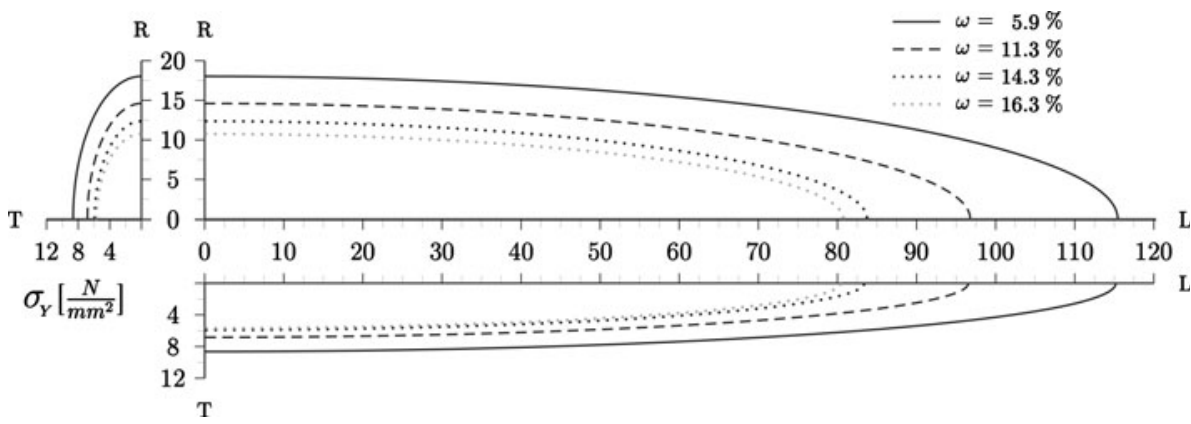

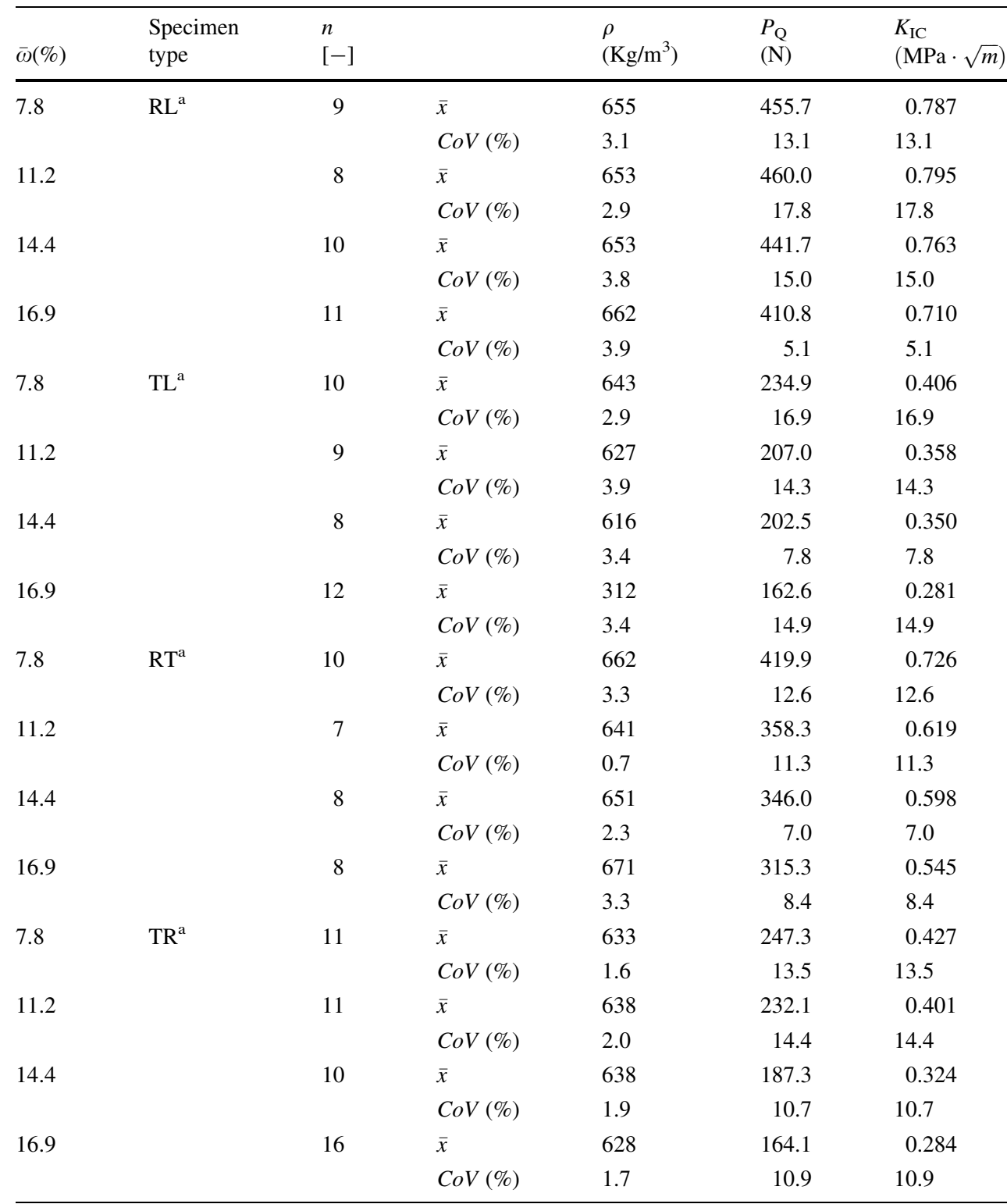

Equally, the critical force $P_{\mathrm{Q}}$, i.e. the force at crack initiation, decreases with increasing MC. This becomes visible especially in the TL and TR loading directions. Compared to the values at $7.8 \% \mathrm{MC}$, the $P_{\mathrm{Q}}$ at $16.9 \% \mathrm{MC}$ is reduced 


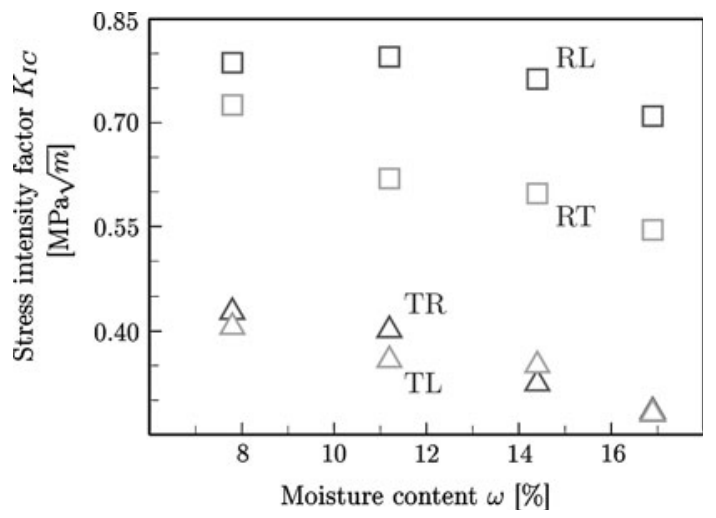

Fig. 8 Moisture-dependent stress intensity factors for European beech wood

by $30.7 \%$ in the TL direction and by $33.6 \%$ in the TR direction. At the same time, the corresponding values in the $\mathrm{RL}$ and RT directions are reduced by 9.8 and $24.8 \%$, respectively. While, compared to the other loading directions, the decline measured in the RL direction is relatively small, in general the fracture properties in the $\mathrm{R}$ direction (loading direction) are less affected by the MC than the properties in the $\mathrm{T}$ direction. This is reflected by the $K_{\mathrm{IC}}$ values in the TL and TR directions, which are influenced by $\mathrm{MC}$ to a higher degree than the values in the RT and RL directions. The $K_{\mathrm{IC}}$ values in the RL and RT directions are approximately twice as high as the values in the TR and TL directions. This, according to [40], can be attributed to the wood rays, which are known to increase wood strength in the $\mathrm{R}$ direction [41, 42]. While no significant difference is found between the $K_{\mathrm{IC}}$ in the TR and TL directions, the $K_{\mathrm{IC}}$ values in the RL direction are on average $\approx 20 \%$ higher than the values in the RT direction.

\section{Conclusions}

The present study provides an overview on the moisturedependent elastic and strength anisotropy of European beech wood in tension. This is exemplified by the two- and three-dimensional visualisation of the compliance matrix and the two-dimensional representation of its yield surface. The elastic and strength parameters published in this research add to a better understanding of the moisturedependent mechanical behaviour of beech wood providing valuable material data which can be used for material simulations allowing for the anisotropic and hygroscopic nature of wood.

The results of this study confirm the distinctive influence of MC on the elastic and strength behaviour of beech wood. They reveal that the Young's moduli, strength and fracture toughness decrease with increasing $\mathrm{MC}$ in all orthotropic directions. Overall, the mechanical properties of beech wood in tension decrease by $\approx 2-3 \%$ for every percent in increased MC. While this is only a rough approximation based on the average values of the properties measured in all orthotropic directions, the given MC-relationship is found to justifiably describe the influence of the MC on the elastic and strength properties in tension. However, it should be emphasised that this relationship applies exclusively to the MC range published in this study. Since it is unlikely that the MC of wood used in structural applications will exceed the tested MC range, for practical purposes, the mentioned approximation is found to be reliable.

Unlike the Young's moduli and the strength properties, the Poisson's ratios examined in this study do not follow a uniform trend with MC. According to the results, no general trend with MC can be formulated for the Poisson's ratios. A comparison with literature data containing moisture-dependent Poisson's ratios determined in compression, revealed a further different behaviour with MC. Supplementary research investigating the moisture dependency of the Poisson's ratios allowing for the differences between the tensile and compressive loading directions might clarify these discrepancies.

Acknowledgements The compact tension tests performed in this research were carried out in the laboratory for Nanometallurgy at the ETH Zürich, Switzerland. The authors would like to express their gratitude to Dr. Diener for providing the equipment and his indispensable help during the experiments.

\section{References}

1. Tiemann HD (1906) Effect of moisture upon the strength and stiffness of wood. U.S Dept. of Agriculture, Forest Service Bul. 70

2. Neuhaus FH (1983) Holz Roh Werkst 41(1):21

3. McBurney RS, Drow JT (1962) The elastic properties of wood: Young's moduli and Poisson's ratios of Douglas-fir and their relations to moisture content. Report No. 1528-D. U.S. Dept. of Agriculture, Forest Service, Forest Products Laboratory Madison, Wisconsin

4. Kretschmann DE, Green DW (1996) Wood Fiber Sci 28(3):320

5. Hering S, Keunecke D, Niemz P (2011) Wood Sci Technol. doi: 10.1007/s00226-011-0449-4

6. Gerhards CC (1982) Wood Fiber Sci 14(1):4

7. Ross RJ (ed) (2010) Wood handbook: wood as an engineering material. General Technical Report FPL-GTR-190. U.S. Dept. of Agriculture, Forest Service, Forest Products Laboratory, Madison

8. Kufner M (1978) Holz Roh Werkst 36(11):435

9. Goulet M (1960) Holz Roh Werkst 18(9):325

10. Östman BAL (1985) Wood Sci Technol 19(2):103

11. Kollmann F (1951) Technologie des Holzes und der Holzwerkstoffe. Springer, Berlin

12. Bodig J, Jayne BA (1993) Mechanics of wood and wood composites. Krieger Publishing Company, Malabar

13. Niemz P (1993) Physik des Holzes und der Holzwerkstoffe. DRWVerlag Weinbrenner GmbH \& Co, Leinfelden-Echterdingen 
14. Schachner H, Reiterer A, Stanzl-Tschegg SE (2000) J Mater Sci Lett 19(20): 1783

15. Frühmann K, Reiterer A, Tschegg EK, Stanzl-Tschegg SE (2002) Philos Mag A 82(17):3289

16. Smith I, Vasic S (2003) Mech Mater 35(8):803-815

17. Schniewind AP, Pozniak RA (1971) Eng Fract Mech 2(3): 223-233

18. Prokopski G (1996) Int J Fract 79(4):R73

19. Reiterer A, Tschegg S (2002) J Mater Sci 37(20):4487. doi: 10.1023/A:1020610231862

20. Vasic S, Stanzl-Tschegg SE (2007) Holzforschung 61:367

21. Scheffler M, Niemz P, Diener M, Lustig V, Hardtke HJ (2004) Eur J Wood Prod 62(2):93

22. Ewing PD, Williams JG (1979) J Mater Sci 14(12):2959. doi: 10.1007/BF00611480

23. Neumann AJ (1998) Ermittlung und Bewertung der elastischen Materialkennwerte von Vollholz in Abhängigkeit der Feuchte und der Anisotropie. Master Thesis, Technische Universität Dresden

24. Wommelsdorf O (1966) Dehnungs- und Querdehnungszahlen von Hölzern. Dissertation, Technische Hochschule Hannover

25. Deutsches Institut für Normung e. V. (DIN) (1979) DIN 52188. Prüfung von Holz; Bestimmung der Zugfestigkeit parallel zur Faser

26. Keunecke D, Hering S, Niemz P (2008) Wood Sci Technol 42(8):633

27. American Society for Testing and Materials (ASTM) (1997) ASTM E399-90. Standard test method for plane-strain fracture toughness of metallic materials
28. Smith I, Landis E, Gong M (2003) Fracture and fatigue in wood. Wiley, Chichester

29. Choi D, Thorpe JL, Hann RB (1991) Wood Sci Technol 25(4): 251

30. Stamer J, Sieglerschmidt H (1933) Z Ver Dtsch Ing 77(19):503

31. Hearmon RFS, Barkas WW (1941) Proc Phys Soc 53(6):674

32. Pozgaj A, Chovanec D, Kuriatko S, Babiak M (1993) Štruktúra a vlastnosti dreva. Priroda, Bratislava

33. Ozyhar T, Hering S, Sanabria SJ, Niemz P (2012) Determining moisture-dependent elastic characteristics of beech wood by means of ultrasonic waves. Wood Sci Technol (accepted for publication)

34. Jeong GY, Hindman DP, Zink-Sharp A (2010) J Mater Sci 45(21):5820. doi:10.1007/s10853-010-4658-2

35. Conners TE, Medvecz CJ (1992) Wood Fiber Sci 24(4):413

36. Grimsel M (1999) Mechanisches Verhalten von Holz. Dissertation, Technische Universität Dresden

37. Hering S, Saft S, Resch E, Niemz P, Kaliske M(2012) Holzforschung 66(3):373

38. Saft S, Kaliske M (2011) Comput Struct 89(23-24):2460

39. Resch E, Kaliske M (2010) Comput Struct 88(3-4):165

40. Stanzl-Tschegg SE (2006) Int J fracture 139(3-4):459

41. Burgert I, Bernasconi A, Eckstein D (1999) Eur J Wood Prod 57(5):397

42. Burgert I, Eckstein D (2001) Trees-Struct Funct 15(3):168 